University of Texas Rio Grande Valley

ScholarWorks @ UTRGV

Management Faculty Publications and

Robert C. Vackar College of Business \&

Presentations

Entrepreneurship

8-1-2021

\title{
Homogamy or Heterogamy: The Effects Of CEO Marriage on Family Firm Performance
}

Xi Yang

Wanrong Hou

The University of Texas Rio Grande Valley

Wencang Zhou

Follow this and additional works at: https://scholarworks.utrgv.edu/mgmt_fac

Part of the Business Administration, Management, and Operations Commons

\section{Recommended Citation}

Xi Yang, Wanrong Hou, and Wencang Zhou, 2021: Homogamy or Heterogamy: The Effects Of CEO

Marriage on Family Firm Performance. Proceedings, 2021, https://doi.org/10.5465/AMBPP.2021.132

This Article is brought to you for free and open access by the Robert C. Vackar College of Business \& Entrepreneurship at ScholarWorks @ UTRGV. It has been accepted for inclusion in Management Faculty Publications and Presentations by an authorized administrator of ScholarWorks @ UTRGV. For more information, please contact justin.white@utrgv.edu,william.flores01@utrgv.edu. 


\title{
HOMOGAMY OR HETEROGAMY: THE EFFECTS OF CEO MARRIAGE ON FAMILY FIRM PERFORMANCE
}

\author{
XI YANG \\ College of Business and Management \\ East Stroudsburg University \\ 200 Prospect Street, East Stroudsburg, PA 18301 \\ WANRONG HOU \\ University of Texas Rio Grande Valley \\ WENCANG ZHOU \\ Montclair State University
}

\section{INTRODUCTION}

In family firms, family and business are intertwined, and family involvement can profoundly impact the firm, such as the pursuit of socioemotional wealth (Aldrich \& Cliff, 2003; Chrisman et al., 2012; Gomez-Mejia et al., 2007). However, most extant studies treat the "family effect" as a black box and fail to identify the mechanism through which family influences the business (Dyer, 2006). In the same spirit, Chrisman, Steier, and Chua (2006) suggest, "any useful theory of family business must include relative statements of how family firms will behave, the conditions that lead to that behavior, and the outcomes of behavior vis-à-vis both family and nonfamily businesses that possess different sets of fundamental characteristics" (p. 719).

Although family business researchers have long been calling to leverage "family science" that describes family-member relationship, family structures, and family events, applications of various family theories in family business studies are scarce (Jaskiewicz et al., 2016). In this study, we focus on a pivotal family member, spouse, and study how a family business owner's spouse (i.e. family CEO spouses) can affect firm performance through individual-level lenshomogamy/heterogamy. In marriage studies, homogamy/heterogamy is a central topic in mate selection theory (Kalmijn, 1994). Homogamy (heterogamy) is a marriage pattern that individuals with similar (dissimilar) traits marry each other. Kalmijn (1994) argues that the phenomenon of homogamy is underpinned by the preference for similar cultural resources, including childrearing values, political attitudes, cultural literacy, taste in art and music, and styles of speech. The value system determines how people interact with others and thus affects the production of relational goods in marriage.

We consider six individual traits - occupation, culture, religion, education, age, and personality - that are widely studied by marriage scholars and examine how the homogamy/heterogamy pattern of each of them can affect family firm performance. We 
contribute the literature by revealing the impact of family CEO spouse from an upper echelon perspective.

\section{THEORETICAL BACKGROUND}

Homogamy, also referred to as assortative mating or positive assortative mating, is a multidisciplinary concept. It describes a pattern that individuals with similar traits mate more frequently with each other. Accordingly, heterogamy, also called disassortative mating or negative assortative mating, means individuals with dissimilar traits have a higher mating probability. Homogamy is universal in human society and animal world (Jiang, Bolnick, \& Kirkpatrick, 2013). Regarding human marriage, extant studies find that homogamy exists in a variety of individual attributes, including intelligence, personality, social and physical characteristics (Epstein \& Guttman, 1984). Sociologists' interests in mating patterns lie in characteristics related to a social boundary, including socioeconomic characteristics, race, ethnicity, and religion (Kalmijn, 1994, 1998). Psychologists focus on the matching of personality traits (Winch et al., 1958). Studies on the couple's economic similarity also attract considerable attention recently (Greenwood, Guner, Kocharkov, \& Santos, 2014). Extant theories on homogamy are summarized into three broad categories: individual preferences for certain characteristics, the influence of social groups, and marriage market constraints (Kalmijn, 1991).

Comparatively, negative assortative mating can be achieved for several reasons. First, Becker's model predicts that the income of two spouses follows a negative assortative mating pattern due to the benefit from a division of labor. Second, exchange theory also predicts negative assortative mating (Davis, 1941; Goode, 1951; Merton, 1941). In the pattern described in exchange theory, two traits are involved, and each spouse possesses one favorable trait. For example, a man who has a superior educational background but a low social class origin can exchange his educational advantage by marrying a woman from a high social class but with low educational attainment. Last, Winch and his colleagues argue a negative assortative mating pattern for psychological characteristics — complementary needs theory (Winch, 1958; Winch et al., 1954).

\section{HYPOTHESIS DEVELOPMENT}

In this section, we develop hypotheses related to six individual characteristicsoccupation, culture, religion, education, age, and personality.

\section{Occupational Homogamy}

Occupation determines an individual's lifestyle to a large extent, given that daily life is organized based on work (Kalmijn, 1994). Couples with different occupations can be beneficial 
because each team member possesses a unique information set that is relevant to decision making quality from an informational perspective (Boone \& Hendricks, 2009). Conversely, couples with the same occupation can develop trust and empathy more easily. Moreover, the same working experience can facilitate mutual support. Thus, we have the following hypothesis:

Hypothesis 1: Occupational homogamy is positively related to family firm performance.

\section{Culture Heterogamy}

Culture is an individuals' values and behaviors. Cultural resources guide how people interact with others and thus affect the production of relational goods such as affection in marriage (Becker, 1981; Kalmijn, 1994; Uhlaner, 1989). However, the same culture may limit the scope of decision making and lead to suboptimal decisions. Therefore, we propose:

Hypothesis 2: Culture heterogamy is positively related to family firm performance.

\section{Religious Homogamy}

Religion has a significant influence on family relationships (Blackwell \& Lichter, 2004; Mahoney, 2010). Because denominational affiliation reflects worldviews and social networks, religious homogamy implies few disagreements about lifestyles and various choices and thus higher marital happiness (Call \& Heaton, 1997; Ellison, Burdette, \& Wilcox, 2010). We propose

Hypothesis 3: Religious homogamy is positively related to family firm performance.

\section{Educational Homogamy}

Education is one of the key characteristics people consider when they choose marriage partners because compared with other status indicators in industrial society, education is a stronger, more stable, and more convenient classification factor (Kalmijn, 1998). Education is a comprehensive reflection of value, belief, and lifestyle which crucial for a long-term commitment (DiMaggio \& Mohr 1985; Kalmijn 1994). Married couples who are educationally dissimilar are more likely to dissolve (Clarkwest, 2007; Schwartz, 2010). Family-to-work conflict can harm organizational performance (Eddleston et al., 2019). In sum, we predict:

Hypothesis 4: Educational homogamy is positively related to family firm performance.

\section{Age Homogamy}


Age is a key factor in the mate selection process. Marriage with at least two years of the older husband is more stable (Heaton, 2002). Age homogamy provides spouses with a common background of experience which can cultivate similar hobbies, value about marriage, and worldviews (Van De Putte et al., 2009). The age gap can lead to a prominent value conflict (Bumpass \& Sweet, 1972). Empirical evidence shows that age heterogamy is associated with a higher risk of marital dissolution (Clarkwest, 2007). We propose:

Hypothesis 5: Age homogamy is positively related to family firm performance.

\section{Psychological Heterogamy}

Compared with demographic characteristics that are surface-level, psychological characteristics are regarded as deep-level (Harrison et al., 1998; Harrison et al., 2002). In general, deep-level characteristics are less visible than demographic characteristics and can only be inferred gradually through verbal and nonverbal communications and exchange of ideas (Harrison et al., 2002). Therefore, studies along this line describe mate selection as a filtering process (Kerckhoff \& Davis, 1962). During this process, people first limit the pool of candidates based on socioeconomic status. Within the same socioeconomic network, candidates who cannot reach a value consensus are eliminated (Byrne, 1971). Last, remaining candidates are selected based on the psychological needs gratified (Winch, 1958). When the psychological needs of spouses are opposite to each other, the spouses' behavior will generate more gratification and higher marital quality. Thus, we have

Hypothesis 6: Psychological heterogamy is positively related to family firm performance.

\section{METHODOLOGY}

\section{Data Collection}

Because no public dataset is available for family business owner-manager's private information, we design a questionnaire to collect data from private family small- and mediumsized enterprises (SMEs). There are two reasons to use SMEs as the research target. First, smaller family firms are "far more representative of family-owned businesses in which there are multiple family members involved in owning and running the business and where family ownership is complete and dominant" (Miller et al., 2008: 52). Second, small family firm CEOs are more likely to include the higher weight of family members' utility, especially spouses', into their decision function.

SME owner-managers are recruited on Qualtrics. Only respondents who (1) lead a family firm with no more than 500 employees, (2) jointly own more $50 \%$ of the firm shares with other 
family members, and (3) currently married are included in the final sample. Eventually, we obtained 254 valid responses.

\section{Measure}

Dependent Variable. We use the income household receives from the family business as our dependent variable $(1=$ Under $\$ 15,000 ; 2=\$ 15,000-\$ 50,000 ; 3=\$ 50,000-\$ 100,000$; $4=\$ 100,000-\$ 250,000 ; 5=\$ 250,000$ and above)

Independent Variables. Our key independent variables are six variables related to homogamy/heterogamy. Religious homogamy is coded 1 if the questions related to the husband and wife have the same answer to the following question and 0 otherwise: "What is your religious affiliation?" (1=Protestant, 2=Catholic, 3=Muslim, 4=Jewish, 5=Hindu, 6=Buddhism, $7=$ Other, and $8=$ Not Religious). Occupational homogamy is coded as 1 if the CEO spouse' occupation is managers/administrators and 0 otherwise. Culture heterogamy is 1 if husband and wife have the different race and 0 otherwise. Educational homogamy is coded as the absolute difference between the husband's and wife's educational attainment score (1=High school or lower, 5=Doctoral). Age homogamy is coded 1 if the husband being 0 to 3 years older or younger than the wife and 0 otherwise (Dribe \& Nystedt, 2017). To measure psychological heterogamy, we choose three pairs of psychological attributes-dominance-abasement, nurturance-succorance and introverted-extroverted. Psychological heterogamy is the average score of the three corresponding questions about the degree to which husband and wife match on each pair of attribute.

Control Variables. We control for seven firm-level and individual-level characteristics: Firm Size (1=9 or less", 2=" 10-49", 3=" 50-99", 4=" 100-249", 5=" 250-499"); Firm Age; Industry Type (1=retailing, $2=$ services, $3=$ manufacturing, 4=other); CEO age; CEO gender $(1=$ female; $0=$ male); $C E O$ education $(1=$ high school or lower, $2=$ some college, no degree, 3 =bachelor's degree, $4=$ master's degree, $5=$ doctorate degree); Founder $(1=$ founder; $0=$ not founder).

\section{RESULTS}

\section{Descriptive Statistics}

The average firm age is 19.1 years. $61.4 \%$ firms have less than 9 employees. Service firms accounts for $53.5 \%$ of sample firms. $51.6 \%$ of family CEOs are female. $70.9 \%$ family CEOs are firm founders. $38.2 \%$ of respondents hold Bachelor's degree. Whites take $74.0 \%$. Mean marriage length is 19.7 years.

\section{Multivariate Analysis}


We use OLS regression to analyze the effect of homogamy and heterogamy variables on firm performance. Hypothesis 1 contends that occupational homogamy predicts high firm performance. The results show that when the CEO spouse's occupation is a manager or administrator, firm performance is 0.31 units higher $(b=0.31, p<0.01)$. The finding suggests common experience and life contribute to the "common language" in marriage and thus the firm performance. So, Hypothesis 1 is supported. Hypothesis 2 proposes that cultural heterogamy predicts good firm performance. The insignificant coefficient suggests that whether a family firm $\mathrm{CEO}$ and his/her spouse have the same cultural background has no impact on firm performance. Hypothesis 2 is not supported. Regarding Hypothesis 3, we find a significant relationship between religious homogamy and firm performance $(b=0.29, p<0.05)$, as predicted. The finding suggests whether a family firm CEO shares the same religious belief with his/her spouse have an impact on firm performance, which is consistent with the findings of Blackwell and Lichter (2004). Hypothesis 3 is supported. We find no support for Hypothesis 4 and 5 that educational homogamy and age homogamy positively predicts firm performance. Psychological heterogamy (CEO and spouse have to match psychological preferences and needs) is expected to improve firm performance in Hypothesis 6. We find psychological heterogamy is significantly related to firm performance as predicted $(b=0.14, p<0.05)$. So, Hypothesis 6 is supported.

\section{DISCUSSION}

In this study, we take a step toward integrating family science into management studies. Specifically, we focus on family firm CEOs' marriage pattern and document that occupational homogamy, religion homogamy and psychological heterogamy have positive effect on family business performance. By examining specific individuals, this study is a response to the call of "putting the family into family business research" (Dyer \& Dyer, 2009).

This study ensures several future research opportunities. First, the scope of this study is family firms and we do not compare family firms and non-family firms. The role of CEO spouses can be different in family firms and non-family firms. Future research could examine how the CEO spouse affects the performance of non-family firms. Second, future research may expand the scope of the current study by including large firms. Although family firms account for the majority of SMEs, a considerable proportion of large firms are also family firms. Given the more mature governance mechanism in large firms, the spousal effect may be more pronounced in terms of emotional support and other influence through the individual channel.

\section{REFERENCES AVAILABLE FROM THE AUTHORS}

